\title{
BIZZY - A Social Game for Entrepreneurship Education
}

\author{
Benjamim Fonseca ${ }^{1,2}$, Ramiro Gonçalves ${ }^{1,2}$, Ricardo Rodrigues Nunes ${ }^{1}$, \\ Mário Sérgio Teixeira ${ }^{1,3}$, Hugo Paredes ${ }^{1,2}$, Leonel Morgado ${ }^{2,4}$, and Paulo Martins ${ }^{1,2}$ \\ ${ }^{1}$ Universidade de Trás-os-Montes e Alto Douro (UTAD), Vila Real, Portugal \\ \{benjaf, ramiro, rrnunes, mariosergio, hparedes, pmartins\} @utad.pt \\ ${ }^{2}$ INESC TEC - INESC Technology and Science, Porto, Portugal \\ ${ }^{3}$ CETRAD, Vila Real, Portugal \\ ${ }^{4}$ Universidade Aberta, Lisboa, Portugal \\ leonel.morgado@uab.pt
}

\begin{abstract}
Entrepreneurship education is increasingly being promoted, driven by a wide consensus in modern societies concerning its benefits in fostering the development of several professional and personal attitudes and skills, such as business expertise, creativity, risk assessment or responsibility. In this context, several authorities have been actively developing policies and activities to empower entrepreneurship culture in young people. Serious Games are recognized as having an important role and potential in education and social networks emerged in the last decade as the platform preferred by many people to socialize, play games or conduct professional activities. This paper presents a proposal for BIZZY, a serious game to be developed and implemented as a Facebook application, to enable young people in the range 12-18 years old to learn entrepreneurial skills progressively, by guiding them to develop a business project from the early idea to the business plan.
\end{abstract}

Keywords: computers in education, entrepreneurship, technology enhanced learning, serious games, social networks, facebook.

\section{Introduction}

In 2012 Global Entrepreneurship Monitor Study about Portugal [1] this country recorded a rate of Early-Stage Entrepreneurial Activity of $7.7 \%$. Among 69 countries involved in GEM 2012 study, this value is only the 44th highest, although it is the 7th highest among the 24 participant innovation oriented economies.

In this study, 38 interviews were also carried out by national experts on entrepreneurship, having these considered that "national culture is few oriented to entrepreneurship and that exists in society, a lack of stimulus to individual success" [1]. These experts also "believe that education and training in the country tend to be partially insufficient" and "evaluate very unfavorably the primary and secondary levels of the education system for their ability to promote entrepreneurial activity", although have "a very positive opinion of higher education in business and management" [1]. 
Games have been adopted exponentially by successive generations over the last 3 decades. More recently, besides the proliferation of console games, mobile and webbased games have also improved hugely, due to their high availability and a distribution model based in advertisement and free access to users.

The emergence of social networks such as Facebook and Twitter, changed the way teenagers and young adults interact, often preferring social network platforms to socialize, share their media and to play games available for free and fully integrated with the social network.

Facebook is nowadays the most used online social network, with a total number of 1.19 billion active users in September 2013, with a 727 million daily average [2], being teenagers and young adults a significant part of them. Facebook is therefore also an attractive media to conduct learning initiatives, taking advantage of the addiction of the vast community of young people and the possibility of conducting game-like activities.

The widespread use of social networking by young people studying at 3 rd cycle and secondary education can be harnessed to encourage alternative learning processes, in particular for the acquisition of entrepreneurship skills. A serious game in the field of entrepreneurship that can be developed for social networking, with fun activities and collaborative tools, can be an innovative teaching tool that motivates young people to learning processes about business and personal development of entrepreneurial skills.

UTAD has accumulated experience in developing this type of serious game for entrepreneurship, thanks to its participation in the European project PLAYER - Play and Learn The Young Entrepreneur (Project ID: ENTR/CIP/09/E/N02S001; Grant Agreement No. 216) where was the institution responsible for the development of a set implemented as an application for Facebook. This game tried to motivate and educate young people to become entrepreneurs capable, supporting the gradual acquisition of entrepreneurial skills through the development of a business idea, along all its stages, to draw up a business plan. Integrating Facebook allowed them to develop their ideas in an environment which they were accustomed and allowed them to go getting feedback from friends and other players.BIZZY is a new serious game for motivating and educating young people to become capable entrepreneurs, and it resulted from previous work developed under the PLAYER project [3]. The game is intended to integrate with Facebook to benefit from a wide community of young people and enable them to develop their ideas inside a well-known environment and provides the ability to follow the required steps while playing and getting feedback from friends, competitors and experts.

The rest of the paper is organized as follows: section 2 presents some recent literature review concerning entrepreneurship education; in section 3 we describe the PLAYER project in which experience and results the BIZZY game was inspired; section 4 presents the BIZZY proposal, outlining its main concepts and innovations introduced; finally, some final remarks are presented in section 5. 


\section{Entrepreneurship Education}

Policy-makers generally consider new venture formation relation with economic growth and technological progress [4] and some studies find those positive effects [5].

Because it can make a significant contribution to this new venture formation, with the development of entrepreneurial attitudes and skills, a wide range of entrepreneurship education efforts has been initiated [6].

Martin, McNally, and Kay [7] did a meta-analysis that suggests a positive association between EE and entrepreneurship-related human capital assets (as knowledge, skills, positive perceptions of entrepreneurship or intentions to become an entrepreneur) and entrepreneurship outcomes (as new venture creation or entrepreneurial performance).

Some research suggests that who had received entrepreneurship education have higher intentions or are more likely to start a business or are more successful in opportunity identification tasks [8-10], compared with those who have not received that type of education.

Because of that, over the past decade, entrepreneurship education (EE) is booming worldwide, not only at the university level, but also in primary and secondary schools, where more and more initiatives and interventions are emerging [11].

Aiming to increase the number of entrepreneurs in Europe, the European Commission developed a plan of action based on 3 pillars, one of which involves developing entrepreneurial education and training to support the growth and business. This pillar is supported in a number of studies suggest that "between $15 \%$ to $20 \%$ of students participating in an entrepreneurship program in secondary education later create his own company, being this number 3 to 5 times higher than for the general population" [12].

The young people who benefit from an entrepreneurial learning develop knowledge about business and a set of skills and attitudes that include creativity, initiative, tenacity, teamwork, understanding of risk and a sense of responsibility that are part of an entrepreneurial mindset [12].

This action plan also recommends that entrepreneurial education follow models of learning with practical experiences and enabling the sharing of experiences with entrepreneurs in the real world.

One entrepreneurial educations method that is used in some schools is "serious games", that allows students with a different environment to practice entrepreneurship, being a playful approach for serious results [13].

For Fayolle [12] the use of internet-based and computer-based technologies could be valuable teaching methods to use in entrepreneurship education.

Gaming aligns learning, play, and participations while exposing students to real challenges in a virtual world, with the expectation of fun [13].

\section{Previous Work - The PLAYER Project}

The PLAYER project [3] was aimed to foster entrepreneurial skills and behaviors in young people using a serious game approach. The project was implemented by an European consortium that promoted an international competition of business ideas. 
The competition was implemented through the PLAYER game, which allowed young players to present and develop their business ideas, describing it with the help of multimedia content, other user's participation and game features that enabled the incremental consolidation of the business concepts and plans. The game was available to the general public of youngsters outside educational environment throughout Europe as well as to high school and university students of the seven countries involved in the consortium of the project.

The game was divided into 4 stages of growing difficulty, gradually introducing entrepreneurial concepts, and aims to leave participants better prepared to start their own business. In the first two stages, participants create their own profile and compile a portfolio that seeks to explain the idea at a conceptual level, using multimedia documents alone. It's also possible to compile an additional portfolio which will not be publicly exhibited, where sensitive critical points of a user's strategy may be revealed to a jury of professionals, or simply use it to include links to additional web documents. Portraying market conditions, the user is faced with uncertainty of the number and the score of votes he/she will attract. This is the phase where lobbying and networking takes place to introduce general public with the business idea.

While the user waits for his portfolio to be voted by other users, he may entertain himself by voting on other portfolios or exploring business strategies and gauging their success with the Sink-or-Swim sub-game. In this sub-game, as one fits together pieces to describe one's strategy, and connects them with verbs that may indicate one's mindset, the whole conceptual map will float or drown in a waving water animation to indicate the likelihood of the company's success.

PLAYER is about easing the users out of what they think they know about business, and making users aware of what they still need to learn and seek out in selfdirected study. Sink-or-Swim is about emphasizing the interrelatedness and long-term consequences of difficult choices that users must make about the way they want to do business. Sink-or-Swim is meant to impress upon users that an idea for a business is made up of definite choices, that making one choice might make other options unobtainable, and that each choice carries risks to the way a business proposes to operate. Risks incurred in one choice need to be mitigated by other choices. A business plan presented to investors can therefore be bold and aggressive while safeguarding return of investment, knowing its limits, and catering to a well-defined market.

Soon thereafter a funding quiz must be taken to assess the level of investment required to start their company up, the user's self-confidence and attitude towards risk. Based on it, a recommendation will be made saying which type of investor to contact, or, eventually, advising the user to rethink his answers. This is to represent financial consultations that would happen in this phase in real life situation. An Executive Summary is then compiled based on information provided in the previous stages, and displayed for the user to complete it with more details on his SWOT analysis and submit it for evaluation by a jury of experts. The left side of Figure 1 shows an example of the Sink-or-Swim game and the right side shows the page seen by the user when reaching the end of the Executive Summary stage. 

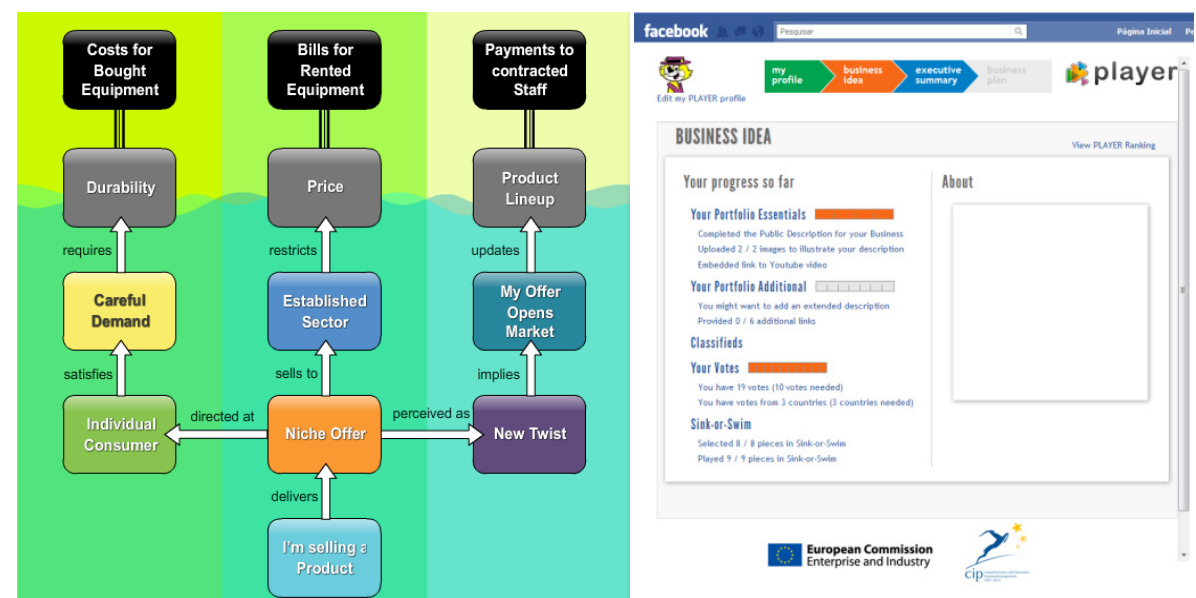

Fig. 1. - Sink-or-Swim game and PLAYER navigation page [3]

While waiting for evaluation, a user may try to get the jury's attention faster by completing weekly challenges, proving he/she is more skilful or more eager to get the attention of evaluators. The user then continues to the last stage, which will require downloading a Business Plan Tool, completing a formal business plan, and uploading it for review. Keeping in mind the 15 to 30 years old target users' age and their inexperience with sometimes complicated business details required in business plans, the game offers them a thorough guidance in the form of Business Plan Tool.

The game had 2706 users registered during the contest period, who completed Stage 1 by just filling their profile. Half of the contestants had secondary or postsecondary school, while the number of users with at least post-graduate education corresponded to $36 \%$ of the total respondents. These results show that the contest reached mostly the target population of 15-30 years old

The users that started using effectively the application by giving a name to the business idea were 2009, a 26\% drop over registered users. Among these, 1446 created business portfolios and only 128 submitted it for voting, completing Stage 2 (5\% of the initial users). These portfolios received votes from 368 users, meaning that a significant number of the users that didn't submit their portfolios for voting still participated and voted in other users' portfolios. There were a total of 2521 votes, with an average of nearly 20 votes per portfolio (it was required 10 votes from 3 different countries to pass to Stage 3) and an average grading of 6.09 (scale 1-10).

Stage 3 was completed by 43 users, who submitted their executive summaries, and only 21 submitted their Business Plan, thus completing Stage 4 and the competition ( $0.4 \%$ of the total users).

Although the considerable participation did not correspond to a number of completed business plans, the overall impression is positive. The reason for not reaching the expected number of business plans can be that the players needed a tutor, to help them in the writing and implementation of management, the short time period of the competition (six months) was an important constrain while some more tangible awards could be a stimulus for the participants to work to a detailed business plan. 
Nonetheless, the high number of entrants to the contest proves people interest and a significant need for entrepreneurial education. PLAYER demonstrated that the concept of business entrepreneurship can be fostered in a short time period (6 months) across several European countries, and gather the attention of thousands of young people, supporting them to rationalize some business concepts.

Player project developed a tool that should be used in a lecturing process as an additional motivator for students to accomplish the requirements needed for business oriented courses. Furthermore, the tool should be applied to the engineering classes that offer wide area of ideas and lack economic background. Working in this direction, the current game could be expanded to further sets of economic, marketing and business management concepts.

PLAYER stimulates creativity (presentation of ideas) more than organized, planned business development (few completed business plans). This confirms other experience with projects related to open communities. The development of individual ideas to concrete opportunities requires mentoring. Some PLAYER's partners experience with this contest is that young students are hardly capable to work on their own. Pupils enjoyed the opportunity to use Facebook as an educational tool but they like to work in groups and they could have some good proficiency if followed by teachers during classes.

Players/learners must see the value to them of the learning and they must strongly believe that they are able to play the game with some challenging goals. In order to make the PLAYER game more attractive to players, the questionnaires and the forms should be made more game-like, providing incentives for players, with instant and transparent achievement scores. Also, explanations why some decisions in the game were proper/improper or why some additional game elements suddenly appeared during the play would improve the serious part of the game - the individual learning process. Player/learner need feedback and dialogue on their process and need time and opportunities for repetition (such us in the Sink-or-Swim game, where player could improve their score following the suggestions provided by the system).

\section{The BIZZY Project}

As we have previously noted, the major use of social networks by young students can and should be used to encourage alternative learning processes, in particular for the acquisition of skills for entrepreneurship. A serious game in the field of entrepreneurship that can be developed for social networking, with fun activities and collaborative tools, can be an innovative teaching tool that motivates young people to processes of learning about business and personal development of entrepreneurial skills.

Previous work with the PLAYER project allowed us to envisage new directions based on the lessons learned by practice and after a careful SWOT analysis of the project process and outcomes. PLAYER has been an innovative project focused on stimulating creativity and inspired potential young entrepreneurs to reflect on business ideas and its formalization. 
According to [3] "Fostering the entrepreneurial spirit of young people through a contest based on a game was pioneering and allowed them to communicate with other competitors, using a social network. Future application should improve this communication aspect. Speaking about entrepreneurship, ideas and businesses should make the players look for the potential realization of their idea".

The BIZZY proposal aims to help developing an entrepreneurial education in young people under 18 years old, improving their business knowledge and skills and entrepreneurial attitudes. The idea is to use a practical approach to teaching and learning that allows the sharing of experiences with others, including guidance from experts and entrepreneurs which could act as mentors from the real world.

This new game will be developed by a multidisciplinary team, covering various scientific fields, encompassing the areas of ICT, Business and Economics.

We propose to create a thus embedded game within the social network facebook, using for that purpose all features of interaction and collaboration.

BIZZY has 4 stages with some innovations comparatively to PLAYER, as described below:

- Evaluation of entrepreneurial skills: this is a new starting step for the game, aiming to assess the player's skills in terms of entrepreneurship, economics and business. This will help to adjust the other game steps according to the player's profile. Moreover, this will help the player to understand his own limitations and capabilities and thus guide him in the inherent learning process;

- Business Idea: involve mentors from the very beginning of the game to have an early validation of the idea, according to predefined criteria. This will still be followed by other players' validation, as was done in PLAYER;

- Business model: improve the sink-or-swim game, combining the original concepts with the CANVAS model [14];

- Business Plan: this was one of the most critical issues in PLAYER, leading to a high dropout rate, due to its complex nature. In this context BIZZY will try to simplify the business plan development, adopting a more game oriented approach, increasing mentoring and providing deeper support through multimedia tutoring materials.

The transition between steps requires overcoming a series of activities and challenges. The most successful players will be awarded with intangible prizes, such as privileged contacts with CEO's, reputed people and experts in the fields of business and entrepreneurship.

PLAYER also exhibited problems related with the overall process. One of them was the short time period of the competition (six months), which will be extended to one year in BIZZY.

In order to disseminate the game to primary and secondary schools nationwide, it is essential to strengthen ties with a number of key partners. Thus, an advisory board will be created for the project, with partners linked to schools and public agencies working in boosting entrepreneurship (representatives of the Ministries of Education and Economics as well as Business associations, municipalities, school principals and Parents and Guardians). 
Finally, another crucial partnership for the success of the project will be established with secondary education teachers, particularly in the areas of ICT and Business / Management, and other school staff.

\section{$5 \quad$ Final Remarks}

Entrepreneurship is nowadays recognized by various stakeholders as a crucial and critical development factor and authorities worldwide have invested increasing public resources in its promotion, including in entrepreneurship education.

Serious games are increasingly being used as educational resources in several contexts, namely as method for learning entrepreneurship skills and attitudes.

Social networks play a key role in the current world, namely among young people. Facebook has a myriad of users that rely on it daily for social interaction of various natures, including sharing information and thus learning in a less structured way.

This paper presented a proposal for a new entrepreneurship education serious game, named BIZZY, that will be implemented in Facebook with young people in the range 12-18 years old enrolled in the national education system. This game is inspired in a previous approach to this educational concept, developed under the PLAYER project, introducing innovations based on the lessons learned.

Acknowledgements. This work is financed by the ERDF - European Regional Development Fund through the COMPETE Programme (operational programme for competitiveness) and by National Funds through the FCT - Fundação para a Ciência e a Tecnologia (Portuguese Foundation for Science and Technology) within project «FCOMP - 01-0124-FEDER-022701

\section{References}

1. Global Entrepreneurship Monitor. GEM Portugal 2012 (2012), http://www . gemconsortium.org $/$ docs $/$ search?doc_cat_id=4\&team_id $=32 \& q \% 20=$ (accessed in January 2014)

2. Facebook Newsroom - Key Facts - Facebook's latest news, announcements and media resources. Facebook (2014), http://newsroom. fb.com/Key-Facts (accessed January 25, 2014)

3. Fonseca, B., et al.: PLAYER - a European Project and a Game to Foster Entrepreneurship Education for Young People. Journal of Universal Computer Science 18(1), 86-105 (2012)

4. Graevenitza, G., Harhoffa, D., Weberb, R.: The effects of entrepreneurship education. Journal of Economic Behavior \& Organization 76, 90-112 (2010)

5. Audretsch, D., Fritsch, M.: Growth regimes over time and space. Regional Studies 36, 113-124 (2002)

6. Kuratko, D.F.: The emergence of entrepreneurship education: development, trends, and challenges. Entrepreneurship Theory and Practice 29(5), 577-598 (2005)

7. Martin, B., McNally, J., Kay, M.: Examining the Formation of Human Capital in Entrepreneurship: A Meta-Analysis of Entrepreneurship Education Outcomes. Journal of Business Venturing 28(2), 211-224 (2013) 
8. Kolvereid, L., Moen, Ø.: Entrepreneurship among business graduates: does a major in entrepreneurship make a difference? Journal of European Industrial Training 21(4), 154160 (1997)

9. Galloway, L., Brown, W.: Entrepreneurship education at university: a driver in the creation of high growth firms? Education and Training. Emerald 44, 398-404 (2002)

10. DeTienne, D.R., Chandler, G.N.: Opportunity identification and its role in the entrepreneurial classroom: a pedagogical approach and empirical test. The Academy of Management Learning and Education 3, 242-257 (2004)

11. Fayolle, A.: Personal views on the future of entrepreneurship education. Entrepreneurship \& Regional Development 25(7-8), 692-701 (2013)

12. European Commission: Entrepreneurship Action Plan (2020), http://ec.europa. eu/enterprise/policies/sme/entrepreneurship2020 / index_en.htm (accessed in February 2014)

13. Neck, H.M., Greene, P.G.: Entrepreneurship Education: Known Worlds and New Frontiers. Journal of Small Business Management 49(1), 55-70 (2011)

14. Osterwalder, A., Pigneur, Y.: Business Model Generation: A Handbook for Visionaries, Game Changers, and Challengers. Wiley (2010) 